\title{
Infant feeding practices among HIV exposed infants using summary index in Sidama Zone, Southern Ethiopia: a cross sectional study
}

\author{
Demewoz Haile ${ }^{1 *}$, Tefera Belachew ${ }^{2}$, Getenesh Birhanu ${ }^{3}$, Tesfaye Setegn ${ }^{4}$ and Sibhatu Biadgilign ${ }^{5}$
}

\begin{abstract}
Background: Combining various aspects of child feeding into an age-specific summary index provides a first answer to the question of how best to deal with recommended feeding practices in the context of HIV pandemic. The objective of this study is to assess feeding practices of HIV exposed infants using summary index and its association with nutritional status in Southern Ethiopia.

Methods: Facility based cross-sectional study design with cluster random sampling technique was conducted in Sidama Zone, Southern Ethiopia. Bivariate and multivariable linear regression analyses were performed to assess the association between summary index (infant and child feeding index) (CS-ICFI) and nutritional status.

Results: The mean ( \pm standard deviation (SD)) cross-sectional infant and child feeding index (CS-ICFI) score of infants was 9.09 ( \pm 2.59 ), [95\% Cl: 8.69-9.49]). Thirty seven percent (36.6\%) of HIV exposed infants fell in the high CS-ICFI category while $31.4 \%$ of them were found in poor feeding index tertile. About forty two percent (41.6\%) of urban infants were found in the high index tertile but only $24 \%$ of the rural infants were found in high index tertile. Forty six percent (46\%) of the rural infants were found in low (poor) feeding index category. The CS-ICFI has a statistically significant association with weight for age $z$ score (WAZ) $(B=0.168, p=0.027)$ and length for age $z$ score $(L A Z)(B=0.183 p=0.036)$. However CS-ICFI was not significantly associated with weight for height z score (WLZ) $(p=0.386)$.

Conclusion: Majority of HIV exposed infants had no optimum complementary feeding practices according to cross-sectional infant and child feeding index. CS-ICFI was statistically associated especially with chronic indicators of nutritional status (LAZ and WAZ). More rural infants were found in poor index tertile than urban infants. This may suggest that rural infants need more attention than urban infants while designing and implementing complementary feeding interventions.
\end{abstract}

\section{Background}

The dilemma posed by Human Immunodeficiency Virus (HIV) pandemic and the risk of mother to child transmission (MTCT) of HIV especially during breast feeding has been a challenge to public health interventions at large [1-3]. Although World Health Organization/ United Nation Children Fund (WHO/UNICEF) has recommended two years of continuous breastfeeding, children born from HIV positive mothers have not been benefited from this recommendation due to the risk of mother to child transmission of the virus. Appropriate

\footnotetext{
* Correspondence: demewozhaile@yahoo.com

${ }^{1}$ Department of Public Health, College of Medicine and Health Sciences,

Madawalabu University, P.o. Box: 139 Bale, Goba, Ethiopia

Full list of author information is available at the end of the article
}

infant and young child feeding practices in the context of HIV should balance the risk of mother to child transmission of the virus and morbidity and mortality from other causes. The new WHO guideline on HIV and infant feeding practices recommended that HIVinfected mothers whose infants are HIV negative or of unknown status to breastfeed exclusively for the first 6 months, then introduce complementary foods and continue to breastfeed for the first 12 months of life [4]. The Ethiopian national guideline for prevention of mother to child transmission (PMTCT) recommends that breast feeding for HIV exposed infants should be continued at least for 12 months and at most for 18 months [5].

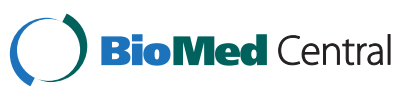

(c) 2014 Haile et al.; licensee BioMed Central Ltd. This is an Open Access article distributed under the terms of the Creative Commons Attribution License (http://creativecommons.org/licenses/by/2.0), which permits unrestricted use, distribution, and reproduction in any medium, provided the original work is properly credited. The Creative Commons Public Domain Dedication waiver (http://creativecommons.org/publicdomain/zero/1.0/) applies to the data made available in this article, unless otherwise stated. 
It is evidenced that malnutrition rate increases during the period of transition from exclusive breast feeding to complementary feeding which might be partly due to inappropriate feeding practices [6]. In fact weight and height gain during infancy are influenced by infant feeding practices [7-9]. The intersecting effect of inappropriate feeding practices among HIV exposed infants followed by malnutrition has been resulted in significant increase in child mortality after 6 months of age [10]. However infant and young child practices are multidimensional and dynamic within short age intervals. Hence, measuring feeding practices of infants and young children greater than 6 months of age is complex [11-13].

Although the challenge has persisted, considerable progress has been made in defining standards and indicators for appropriate complementary feeding practices through the development of indicators for assessing infant and young child feeding practices [14]. The previously developed indicators could not able to show the simultaneous effect of different dimension of complementary feeding and has focused on single practices over a narrow age range and has not addressed the impact of adequate or optimal infant and child feeding [15]. Therefore developing an index which able to reflect both feeding behavior and diet quality in measuring feeding practices of infants greater than 6 months of age at a time is important [16]. Besides to this, quantifiable summary index increases the comparability of findings of different studies in the area of child feeding $[13,15]$.

So far infant and child feeding index (ICFI) has only been used for non HIV exposed children. The application of this summary index for assessing feeding practices of HIV exposed infants is not known in Ethiopia by considering the current feeding recommendations for HIV exposed infants.

Therefore, the objective of this study is to assess the infant feeding practices of HIV exposed infants using summary index and its association with their nutritional status in Sidama zone, Southern Ethiopia which would provide policy makers, program implementers and care providers with evidence-based information on optimal complementary feeding practices of HIV exposed infants.

\section{Methods}

\section{Study setting and sample}

This study was conducted in Sidama zone which is one of the zones in South Nation, Nationalities and People Regional state (SNNPR) of Ethiopia. Fifty percent (50.48\%) of the total population was male while $49.51 \%$ were female [17]. A substantial area of Sidama land produces coffee, which is the major cash crop in the region, and larger number of the population is known to heavily depend on 'Enset' (false Banana). The staple foods in Sidama Zone are maize and kocho [18]. Kocho is bulky, chewy, fermented starch bread which is made from a mixture of the decorticated leaf sheaths and grated root.

A facility-based cross-sectional study was conducted in randomly selected 10 government health institutions which were providing ART (antiretroviral therapy) and PMTCT (prevention of mother to child transmission) services in Sidama Zone, Southern Ethiopia between February and April 2012. There were 18 health institutions which were providing ART and PMTCT services for HIV positive mothers with their HIV exposed infants. From the total of 18 health institutions, four were excluded based on the exclusion criteria and the remaining fourteen health institutions were considered as cluster and ten health institutions (clusters) were selected randomly. All $(\mathrm{n}=184)$ HIV exposed infantmother pairs from randomly selected health institutions were included in the study. Those mothers who have HIV exposed infant of aged 6-17 months and absence of serious illness of the mother or infant were the inclusion criteria's. Infants were excluded from the study if they were not exposed to HIV or if they were diagnosed as HIV-positive prior to data collection. None of the mothers who fulfill the eligibility criteria were found to refuse to participate in the study. A pre-tested structured questionnaire was used to collect socio-demographic and feeding practices of HIV exposed infant. Feeding practices were assessed by the qualitative 24 recall method and 7 day quasi food group frequency. Health professionals were recruited and trained for two days on data collection techniques. The data collection process was closely supervised and collected data were checked for completeness and inconsistencies in the field.

\section{Anthropometric measurements}

All anthropometric measurements were taken by trained nurses with their respective assistants. Length of the infants (6-17 months) was measured in a recumbent position to the nearest $0.1 \mathrm{~cm}$ using a locally made wooden sliding board with an upright wooden base and movable headpiece. Weight was measured in kilogram to the nearest $0.1 \mathrm{Kg}$ by Salter hanging scale. Calibration of instrument against zero reading was checked after weighting every infant. Instruments were checked against a standard weight for its accuracy daily. Infants were weighed with light clothing and without shoes.

\section{Cross-sectional infant and child feeding index (CS-ICFI)}

The CS-ICFI were constructed using the method proposed by Ruel and Menon [15] and adapted to the local context and to the current recommendation (Table 1). The 24 hour dietary diversity score is a sum score of: Grains + Tubers + Milk + Vitamin A-rich fruits/vegetables + other fruits/vegetables/juice + Animal source foods + Legumes + Fats (received, or did not receive each 
Table 1 Feeding practices and scoring system used to create infant/child feeding index for HIV exposed infants aged 6-17 months, by age group, 2012

\begin{tabular}{|c|c|c|c|}
\hline Variables & 6-9 months & $9-11$ months & $12-17$ months \\
\hline \multirow[t]{2}{*}{ Current breast feeding } & $\mathrm{No}=0$ & $\mathrm{No}=0$ & $\mathrm{No}=1$ \\
\hline & Yes $=2$ & Yes $=2$ & Yes $=1$ \\
\hline \multirow[t]{2}{*}{ Bottle feeding (24 Hrs recall) } & Yes $=0$ & $Y e=0$ & Yes $=0$ \\
\hline & $\mathrm{No}=1$ & $\mathrm{No}=1$ & $\mathrm{No}=1$ \\
\hline \multirow[t]{3}{*}{ Dietary diversity (past 24 hours) } & $\begin{array}{l}\text { None of the foods/groups: } \\
\text { Score }=0\end{array}$ & None of the foods groups :Score $=0$ & $\begin{array}{l}\text { None or one of the foods/groups: } \\
\text { Score }=0\end{array}$ \\
\hline & One food group: score $=1$ & One to two foods groups: Score $=1$ & Two or three foods/groups: Score $=1$ \\
\hline & $\begin{array}{l}\text { Two or more food groups: } \\
\text { score }=2\end{array}$ & Three or more food groups: Score $=2$ & Four or more foods/groups: Score $=2$ \\
\hline Frequency of feeding & Not at all: Score $=0$ & Not at all: Score $=0$ & Not at all or once: Score $=0$ \\
\hline \multirow[t]{3}{*}{ solids/semi-solids (past 24 hours) } & Once: Score $=1$ & Once or twice: Score = 1 & Twice: Score $=1$ \\
\hline & 2 or more times: Score $=2$ & 3 or more times: Score $=2$ & Three times: Score $=2$ \\
\hline & & & Four times or more: Score $=3$ \\
\hline \multirow[t]{3}{*}{ Seven day qusi food group frequency ${ }^{@}$} & $\begin{array}{l}0 \text { (no foods prev. week): } \\
\text { Score }=0\end{array}$ & 0 or $1:$ Score $=0$ & 0 through 3: Score $=0$ \\
\hline & 1 or 2 : Score $=1$ & 2 through $4:$ Score $=1$ & 4 through $6:$ Score $=1$ \\
\hline & 3 or higher: Score $=2$ & 5 or higher: Score $=2$ & 7 or higher: Score $=2$ \\
\hline \multirow{2}{*}{$\begin{array}{l}\text { Mother reports hand washing before } \\
\text { cooking food }\end{array}$} & Yes $=1$ & Yes $=1$ & Yes $=1$ \\
\hline & No $=0$ & No $=0$ & $\mathrm{No}=0$ \\
\hline \multirow[t]{2}{*}{ Wash hand before feeding the child } & Yes $=1$ & Yes $=1$ & Yes $=1$ \\
\hline & $\mathrm{No}=0$ & $\mathrm{No}=0$ & $\mathrm{No}=0$ \\
\hline \multirow[t]{2}{*}{ Does the infant get help to eat yesterday? } & Yes $=1$ & Yes $=1$ & Yes $=1$ \\
\hline & No $=0$ & $\mathrm{No}=0$ & No $=0$ \\
\hline \multicolumn{4}{|l|}{$\begin{array}{l}\text { What does caregiver do when child } \\
\text { refuses to eat? }\end{array}$} \\
\hline A) Nothing (child left alone) & $a=0$ & $a=0$ & $a=0$ \\
\hline B) Other * & $b=1$ & $b=1$ & $b=1$ \\
\hline Total (maximum , minimum) & 13,0 & 13,0 & 13,0 \\
\hline
\end{tabular}

${ }^{*}$ coax, play with, force, change food, not a problem., @ This is a modified food group frequency, where the questions are asked in the form, How many days in the last seven days was (name) given (food group)?,i so that the number entered for each child is the number of days, with a maximum of seven, not the number of times the child ate a food from the group.

food/group). Scores were assigned to reflect the agespecific distributions of HIV exposed infants in tertiles. The seven day quasi food frequency is a modified food group frequency and measured as "How many days in the last seven days was given [food group]?" The number of days that a food group has consumed recorded for each child with a maximum of seven days.

The list of foods summed is the same as for the 24-hour diversity score, with the exception that grains have been combined with roots/tubers. In seven day food group frequency score, each food group is scored 0 if not given to the infant in the previous week, scored +1 if given one to three days, and +2 if given four or more days in the previous week. These scores are then summed to give a possible range of 0 to 14 and the seven days food group frequency scores were assigned to reflect the age-specific distributions of study participants in tertiles. The CS-ICFI was developed with values $0-13$ and it was divided into 3 categories (tertiles) in the following manner: a sum scores of 0-7 categorized as low CS-ICFI, sum scores of 8-10 categorized as medium CS-ICFI, and sum scores of 11-13 were classified as high CS-ICFI.

\section{Statistical analysis}

Data were checked for completeness, consistencies, cleaned, coded and entered to SPSS for windows version 20.0. It was exported to WHO Anthro for nutritional status analysis. Descriptive statistics (mean, standard deviation, minimum, maximum, and median) were computed for all continuous variables and frequency distribution was carried out to evaluate the distribution of categorical variables. Homogeneity of variance and normality assumption were tested and found that the data was fit for ANOVA analysis and independent $t$-test. Bivariate analyses (independent $t$-test or one 
way ANOVA) were carried out at the first stage. Then multivariable linear regression model was fitted to identify independent association between CS-ICFI and nutritional status of HIV exposed infants. All tests were two-sided and $\mathrm{p}<$ 0.05 was considered for statistical significance. The internal consistency of the CS-ICFI was measured by the Cronbach's $\alpha$ coefficient. The Cronbach's $\alpha$ value higher than 0.7 was generally considered to be satisfactory [19]. The anthropometric indices were computed and compared with reference data from World Health Organization growth chart 2007. Children below-2SD of the WHO median weight-for-age, height-for-age and weight-for-height were considered as underweight, stunted and wasted, respectively.

Ethical approval was received from institutional review board (IRB) of Hawassa University. Official letter of cooperation was also obtained from Sidama Zone Health Department. Informed verbal consent was secured from study participants in their own language after explaining the purpose of the study, potential risk and benefits of participating in the study. The right of respondents to withdraw from the study any time was assured. The participants were also assured about the confidentiality of the data.

\section{Result}

\section{Socio-demographic characteristics}

A total of 184 HIV positive mothers having HIV exposed infants of aged 6-17 months were included in the study. The mean $( \pm \mathrm{SD})$ age of mothers was $28.85( \pm 5.4)$ years. About fifty five percent (54.9\%) of the respondents were protestant by religion and 77 (43.03\%) were illiterates by educational status. Majority 158 (84.5\%) were married and $134(72.8 \%)$ of the respondents were urban residents (Table 2).

\section{Cross sectional infant and child feeding index score of infants (CS-ICFI)}

The mean $( \pm \mathrm{SD})$ cross sectional infant and child feeding index (CS-ICFI) score of infants was $9.09( \pm 2.59)$, [95\% CI: 8.69-9.49]. The mean $( \pm S D)$ CS-ICFI scores for respective age groups were $8.19( \pm 2.71)$, [95\% CI: 7.588.85], 9.33 ( \pm 2.37 ), [95\% CI: 8.57-10.09] and 9.85 ( \pm 2.39 ), [95\% CI: 9.22-10.35] for infants 6-8 months of age, 9-11 months of age and 12-17 months of age respectively. There was a statistically significant difference in mean CS-ICFI among those age groups $(\mathrm{p}=0.002)$. The infant and child feeding index score varied from a minimum of 3 to a maximum of 13 (for a theoretical maximum of 13). About thirty seven percent (36.6\%) of infants were under high CS-ICFI tertile while (31.4\%) of them were found in the low CS-ICFI tertile (Figure 1).

There was a statistically significant difference in CS-ICFI mean scores of urban and rural infants (9.34 Vs 8.44) $(p=0.037)$. About $41.6 \%$ of urban infants were found in
Table 2 Socio-demographic characteristics of mothers having HIV exposed infants in Sidama Zone, Southern Ethiopia, 2012

\begin{tabular}{|c|c|c|}
\hline Socio-demographic characteristics & Frequency & Percentage \\
\hline \multicolumn{3}{|l|}{ Age of the mother(years) $(n=179)$} \\
\hline$\leq 24$ & 28 & 15.6 \\
\hline $25-29$ & 73 & 40.8 \\
\hline$\geq 30$ & 78 & 43.6 \\
\hline \multicolumn{3}{|l|}{ Religion( $n=184)$} \\
\hline Protestant & 101 & 54.9 \\
\hline Orthodox & 64 & 34.8 \\
\hline Muslim & 15 & 8.2 \\
\hline Catholic & 4 & 2.2 \\
\hline \multicolumn{3}{|l|}{ Ethnic group of mothers $(n=184)$} \\
\hline Sidama & 62 & 33.7 \\
\hline Amhara & 37 & 20.1 \\
\hline Gurage & 30 & 16.3 \\
\hline Oromo & 28 & 15.2 \\
\hline Wolayita & 17 & 9.2 \\
\hline Others * & 10 & 5.4 \\
\hline \multicolumn{3}{|l|}{ Marital status $(n=181)$} \\
\hline Married & 158 & 84.5 \\
\hline Widowed & 12 & 6.5 \\
\hline Divorced & 11 & 7.61 \\
\hline \multicolumn{3}{|l|}{ Place of residence $(n=184)$} \\
\hline Urban & 134 & 72.8 \\
\hline Rural & 50 & 27.2 \\
\hline \multicolumn{3}{|l|}{ Educational status $(\mathrm{n}=179)$} \\
\hline |lliterate $e^{\varepsilon}$ & 77 & 43.03 \\
\hline Read /write & 8 & 4.47 \\
\hline Primary education (1-8) & 53 & 29.61 \\
\hline Secondary education $\left(9^{+}\right)$ & 41 & 22.92 \\
\hline \multicolumn{3}{|l|}{ Sex of infant $(n=184)$} \\
\hline Male & 106 & 57.6 \\
\hline Female & 78 & 42.4 \\
\hline
\end{tabular}

Ethose who didn't attend any formal education *Tigre, Kambata and Gamo.

the high index tertile but only $24 \%$ of the rural infants were found in high index tertile. The prevalence of low (poor) feeding index tertile was $46 \%$ in the rural infants (Figure 2). ART status (pre-ART or on ART) and disclosure of HIV status were not statistically associated with CS-ICFI tertiles ( $p>0.05)$. But the time when the mother know their sero status has statistically significant association with CS-ICFI category $(\mathrm{p}=0.022)($ Table 3$)$.

\section{Evaluation of the internal consistency of CS-ICFI}

The internal consistency of the index was estimated by the Cronbach's $\alpha$ coefficient [19]. The Cronbach's $\alpha$ coefficient 


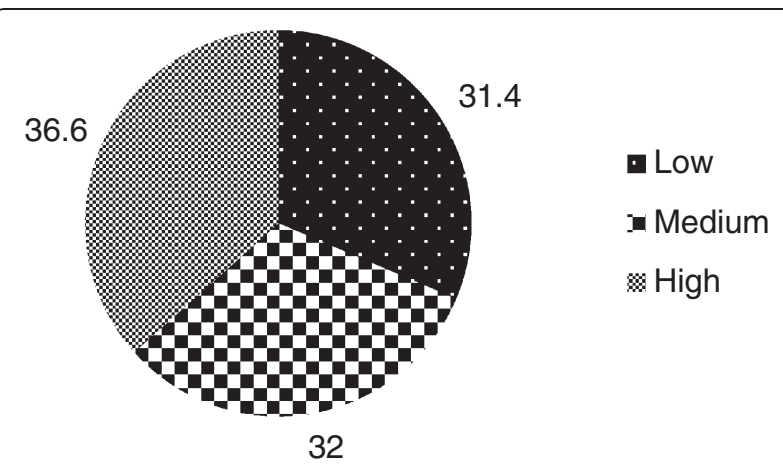

Figure 1 Distribution of HIV exposed infants by their feeding index tertile in Sidama Zone, South Ethiopia, 2012.

of this study was more or less similar among the different age groups. But the Cronbach's $\alpha$ value was slightly higher for older age groups. The CS- ICFI internal consistency was good for infants aged 9-11 months $\alpha=0.70$ (95\% CI: $0.49-0.80$ ) and aged $12-17$ months $\alpha=0.71$ (95\% CI: $0.55-0.78)$, and it was lower for infants aged $6-8$ months $\alpha=0.68$ (95\% CI: 0.54-0.77).

The CS-ICFI showed strong correlation with 24 hour food frequency score, 24 hour food diversity score and seven day food group frequency. The correlation between current breast feeding score and CS-ICFI decreased in the older age groups. In youngest and oldest age groups, removing breast-feeding and bottle-feeding from the index improved the value of Cronbach's $\alpha$ coefficient to the acceptable range $(\geq 0.70)$. For all age groups removing the bottle feeding from the index improved the value of the Cronbach's $\alpha$ coefficient to the acceptable range $(\geq 0.70)$ (Table 4$)$.

\section{Association between nutritional status and CS-ICFI}

Forty two (23.7\%) of the HIV exposed infants were stunted and 27 (15.3\%) were underweight while 23 (13.5\%) were wasted. The mean WLZ, LAZ and WAZ was $-0.19,-0.86$, and -0.72 , respectively.
The bivariate analysis showed that the mean LAZ and WAZ score of HIV exposed were statistically different across with CS-ICFI tertiles (Table 5). Multivariable linear regression analysis was also performed to determine the statistical association between CS-ICFI and WAZ after controlling the effect of potential confounders. After adjusting for diarrheal morbidity in the last two weeks, WAZ score was significantly associated with CS-ICFI $(ß=0.168, p=0.027)$. The association between CS-ICFI and LAZ scores was statistically significant. Monthly income (positively) $(\mathrm{p}=0.022)$ and pre-lacteal feeding (negatively) $(\mathrm{p}=0.048)$ were independent predictors of LAZ score (Table 6).

The interaction effects of child, maternal or household characteristics on the association between ICFI tertiles and infant nutritional status was checked by interaction model. None of those characteristics have interaction effect on the association between CS-ICFI and nutritional status (LAZ and WAZ scores) of HIV exposed infants.

\section{Discussion}

This study has assessed feeding practices of HIV exposed infants using a cross sectional summary index which summarize key complementary feeding practices in to a composite index by considering the current infant feeding recommendations. The mean $( \pm$ SD) CS-ICFI score was $9.09( \pm 2.59)$ (95\% CI: 8.69-9.49). This finding is significantly higher than the mean score reported in Rwanda which is 8.04 [20]. The difference might be due to the difference in age category of study subjects. The study done in Rwanda included younger infants (6-15 months) as compared to the current study (6-17 months). The mean CS-ICFI score of the youngest age group infants was significantly different from mean CS-ICFI score of oldest age group $(p=0.002)$. Other studies also reported that the older age groups had higher mean index score $[21,22]$. This implies that complementary feeding practices among HIV exposed infants around initiation of complementary feeding practices are less optimal as

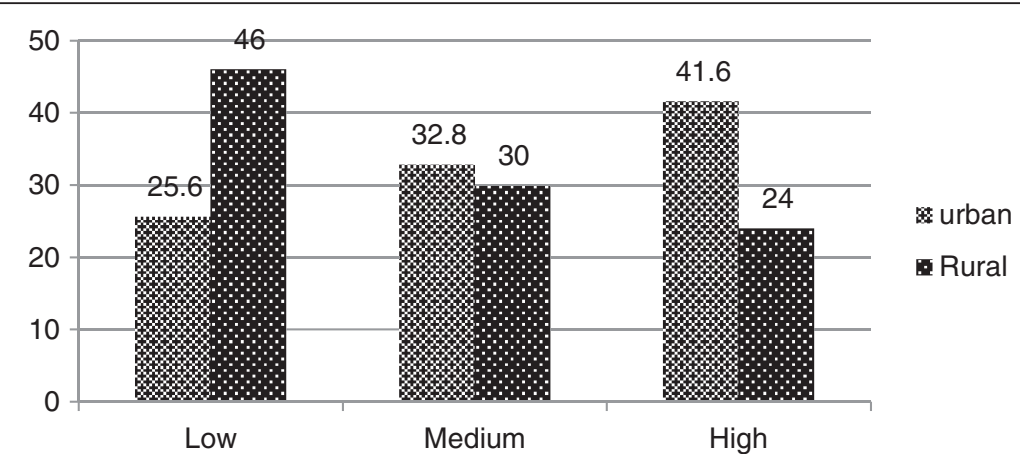

Figure 2 Distribution of CS-ICFI tertiles by place of residence among HIV exposed infants in Sidama Zone, South Ethiopia, 2012. 
Table 3 Association of CS-ICFI of HIV exposed infants and maternal characteristics in Sidama Zone, South Ethiopia, 2012

\begin{tabular}{|c|c|c|c|c|c|c|c|c|}
\hline \multirow[t]{4}{*}{ Characteristics } & & \multicolumn{6}{|c|}{ CS-ICFI tertiles } & \multirow[t]{4}{*}{$P$ value } \\
\hline & & \multirow{2}{*}{\multicolumn{2}{|c|}{$\begin{array}{c}\text { Low } \\
\text { CS-ICFI }\end{array}$}} & \multirow{2}{*}{\multicolumn{2}{|c|}{$\begin{array}{l}\text { Medium } \\
\text { CS-ICFI }\end{array}$}} & \multirow{2}{*}{\multicolumn{2}{|c|}{$\begin{array}{c}\text { High } \\
\text { CS-ICFI }\end{array}$}} & \\
\hline & & & & & & & & \\
\hline & & No & $\%$ & No & $\%$ & No & $\%$ & \\
\hline \multirow[t]{2}{*}{ ART status } & Pre ART & 24 & 43.6 & 15 & 27.3 & 18 & 28.1 & 0.115 \\
\hline & On ART & 31 & 56.4 & 40 & 72.7 & 46 & 71.9 & \\
\hline \multirow{2}{*}{$\begin{array}{l}\text { Disclosure of } \\
\text { HIV status }\end{array}$} & Yes & 47 & 85.5 & 49 & 87.5 & 55 & 85.9 & 0.947 \\
\hline & No & 8 & 14.5 & 7 & 12.5 & 9 & 14.1 & \\
\hline \multirow{3}{*}{$\begin{array}{l}\text { Stigma and } \\
\text { discrimination }\end{array}$} & Yes & 3 & 5.5 & 8 & 14.3 & 4 & 6.2 & 0.200 \\
\hline & No & 53 & 94.5 & 48 & 85.7 & 60 & 93.8 & \\
\hline & No & 48 & 87.3 & 42 & 75 & 30 & 47.6 & \\
\hline \multirow[t]{4}{*}{$\begin{array}{l}\text { When you know } \\
\text { your HIV status }\end{array}$} & $\begin{array}{l}\text { Before } \\
\text { pregnancy }\end{array}$ & 21 & 38.2 & 32 & 57.1 & 35 & 54.7 & $0.022^{*}$ \\
\hline & $\begin{array}{l}\text { During } \\
\text { pregnancy }\end{array}$ & 30 & 54.5 & 16 & 28.6 & 18 & 28.1 & \\
\hline & During birth & 2 & 3.6 & 1 & 1.8 & 1 & 1.6 & \\
\hline & After birth & 2 & 3.6 & 7 & 12.5 & 10 & 15.6 & \\
\hline
\end{tabular}

*significant $p$ value $<0.05$.

compared with complementary feeding practice on the older age time.

There was significant difference in CS-ICFI mean scores between urban and rural infants (9.34 Vs 8.44) $(\mathrm{p}=0.02)$. Similar finding was reported from China in which the mean CS-ICFI scores between urban and rural infants were significantly different $(\mathrm{p}<0.05)[12,23]$. The internal consistency of the index for the whole sample was a little below the acceptable limit (0.67 Vs 0.70) [19]. But removing either bottle feeding or breast feeding from the index increased the Cronbach's $\alpha$ coefficient to the acceptable range. This indicated that breast feeding and bottle feeding had weak or negative correlation with other complementary dimensions. This again implicate that bottle feeding and breast feeding practice displace other complementary feeding practices. This finding is consistent with the study done in rural Senegal that omitting breast feeding component from the index increase value to 0.82 [24]. In the current study the internal consistency of CS- ICFI was good for children aged 9-11 months $(\alpha=0.70)$ and for those aged $12-17$ months $(\alpha=0.71)$, but it was lower for infants aged 6-8 months $(\alpha=0.68)$. This showed that CS-ICFI is a reliable measure of complementary feeding practices for infants aged 9 months and above. The lower internal consistency of the CS-ICFI for infants of age 6-8 months resulted from higher prevalence of breast feeding practices in this age group as compared to older age groups $(p=0.003)$. However, this finding is not consistence with the finding from rural Burkina Faso which showed that the internal consistency was good for the youngest infants $(6-11$ months) $(\alpha=0.79)$ and lower among children aged 12-23 months (Cronbach's $\alpha=0.63$ ) [25]. This contradiction might be due to the difference in the practices of breast feeding and the socio cultural difference between the two communities. Breast-feeding was almost ubiquitous and was prolonged (even above two years) in Burkina Faso.

In this study, $36.6 \%$ of HIV exposed infants were in high CS-ICFI tertile while $31.4 \%$ of them were in lower CS-ICFI tertile. However, the age specific ICFI analysis showed that most of the infants (48.4\%) in the youngest age group (6-8 months) were found in the lower CS-ICFI category while most (48.5\%) of the infants in the oldest age groups (12-17 months) found in the medium CS-ICFI tertile. This finding is consistent with a study done in rural Burkina Faso which showed that among infants of

Table 4 Internal consistency of CS-ICFI and its correlation with ICFI components among HIV exposed infants in Sidama Zone, South Ethiopia, 2012

\begin{tabular}{|c|c|c|c|c|c|c|c|c|}
\hline \multirow{4}{*}{$\begin{array}{l}\text { Cronbach's } \alpha^{\xi} \\
\text { Components of ICFI }\end{array}$} & \multirow{2}{*}{\multicolumn{2}{|c|}{ All $(n=175)$}} & \multirow{2}{*}{\multicolumn{2}{|c|}{ 6-8 months $(n=69)$}} & \multirow{2}{*}{\multicolumn{2}{|c|}{$\begin{array}{c}9-11 \text { months } \\
(n=44)\end{array}$}} & \multirow{2}{*}{\multicolumn{2}{|c|}{$\begin{array}{c}12-17 \\
\text { months }(n=62)\end{array}$}} \\
\hline & & & & & & & & \\
\hline & \multicolumn{2}{|c|}{0.67} & \multicolumn{2}{|c|}{0.68} & \multicolumn{2}{|c|}{0.70} & \multicolumn{2}{|c|}{0.71} \\
\hline & $r^{*}$ & $\alpha^{\prime \prime}$ & $r^{*}$ & $\alpha^{\prime \prime}$ & $r^{*}$ & $\alpha^{\prime \prime}$ & $r^{*}$ & $\alpha^{\prime \prime}$ \\
\hline Meal frequency score ${ }^{\#}$ & 0.81 & 0.56 & 0.77 & 0.55 & 0.68 & 0.6 & 0.78 & 0.59 \\
\hline Dietary diversity score ${ }^{\#}$ & 0.80 & 0.59 & 0.69 & 0.55 & 0.61 & 0.61 & 0.73 & 0.62 \\
\hline 7 day food frequency & 0.71 & 0.6 & 0.53 & 0.56 & 0.4 & 0.64 & 0.61 & 0.64 \\
\hline Psycho social support during food refusal ${ }^{\#}$ & 0.32 & 0.67 & 0.33 & 0.68 & 0.27 & 0.67 & .0 .50 & 0.67 \\
\hline Infant get help to eat ${ }^{\#}$ & 0.65 & 0.65 & 0.44 & 0.65 & 0.35 & 0.65 & 0.56 & 0.66 \\
\hline Bottle feeding ${ }^{\#}$ & -0.15 & 0.71 & 0.41 & 0.72 & -0.06 & 0.70 & 0.10 & 0.72 \\
\hline Washing hands before cooking child food" & 0.67 & 0.67 & 0.29 & 0.67 & 0.20 & 0.67 & 0.24 & 0.68 \\
\hline Wash hands before feeding $\#$ & 0.67 & 0.67 & 0.28 & 0.55 & 0.23 & 0.67 & 0.39 & 0.69 \\
\hline Current breast feeding $\#$ & 0.02 & 0.71 & 0.46 & 0.72 & 0.27 & 0.66 & 0.27 & 0.70 \\
\hline
\end{tabular}

$\bar{c}^{c} \alpha$ value when all items included *correlation of each component with CS-ICFI " $\alpha$ value when Item removed, " 24 hour recall. 
Table 5 Bivariate association (one way ANOVA) of CS-ICFI and nutritional status among HIV exposed infants in Sidama Zone, South Ethiopia, 2012

\begin{tabular}{lccccc}
\hline Nutritional status & \multicolumn{3}{c}{ CS-ICFI } & F value & P value \\
\cline { 2 - 4 } & Low & Medium & High & & \\
\hline Mean WLZ & 0.12 & -0.29 & -0.28 & 0.957 & 0.386 \\
Mean WAZ† & -1.12 & -0.60 & -0.43 & 3.611 & $0.029 \&$ \\
Mean LAZ & -1.70 & -0.54 & -0.31 & 3.621 & $0.029 \&$ \\
\hline
\end{tabular}

${ }^{\wedge}$ weight for length $\mathrm{Z}$ score ${ }^{\dagger}$ weight for age $\mathrm{Z}$ score ${ }^{\star}$ length for age $\mathrm{Z}$ score \&statistically significant at $p<0.05$ (two-tailed).

aged $6-11$ months, $52 \%, 23 \%$ and $25 \%$ were found in the poor, average and good feeding index while among children of aged 12-23 months 35\%, 37\%, 28\% were found in poor, medium and good feeding index category respectively [25].

This study showed that there was a statistically significant difference in mean LAZ and WAZ even after controlling the potential confounders. A similar finding was reported from India which revealed that LAZ and WAZ had showed significant association with ICFI [13]. Another study from India showed that complementary feeding index was associated with LAZ score but not with WAZ and WLZ scores [21]. On the other hand a study conducted in Bangladesh reported that the mean LAZ score of children aged 12-23 months was significantly higher among those who were at the upper ICFI tertile compared to those who were at the middle or lower ICFI tertile ( -2.01 and -3.20 respectively) [26]. A similar study done in Rwanda indicated that ICFI was positively associated with WLZ and WAZ scores. However, neither the ICFI nor any of its components were associated with the LAZ score [27]. There was also a study from rural Senegal reported that feeding index was not associated with either height-for-age or with linear growth [28]. But a study from China indicated that ICFI was associated with both WAZ and WLZ scores, and did not show statistically significant association with children's LAZ score [22] which could be due to the differences in the participants' age group in

Table 6 Multivariable linear regressions to identify association between LAZ score and CS-ICFI among HIV exposed infants in Sidama Zone, South Ethiopia, 2012

\begin{tabular}{lcc}
\hline Variables & \multicolumn{2}{c}{ LAZ } \\
\cline { 2 - 3 } & B & P value \\
\hline Marital status(married) & 0.054 & 0.505 \\
Monthly income & 0.199 & $0.022^{\dagger}$ \\
Pre lacteal feeding & -0.162 & $0.048^{\dagger}$ \\
Age at introduction of CF & -0.062 & 0.501 \\
CS-ICFI & 0.183 & $0.036^{\dagger}$
\end{tabular}

$B=$ standardized regression coefficients $\mathrm{CF}=$ Complementary Feeding ${ }^{\dagger}$ statistically significant at $p<0.05$ (two-tailed). which the study participants in China were infants of aged 6-11 months. This justification is further supported by a study conducted in Latin America which conclude that the association between feeding practices and HAZ score of children was generally weaker and less consistent among children in 12 months of life but increased gradually with age [29]. The Latin American study explained the observed statistical association between feeding practices and LAZ in older infants as compared to their younger infants could be explained by the clustering/cumulative effects of previous feeding practices. In the current study the difference in mean WAZ and LAZ scores between the lowest and the highest tertile was 0.69 and 1.39 respectively. This mean difference in $\mathrm{Z}$ score between the two extreme CS-ICFI tertiles was statistically significant and biologically important for both WAZ and LAZ [30]. In this study, WLZ score was not associated with CS-ICFI which is consistent with other studies $[21,26]$.

Presence of statistically significant association between CS-ICFI and WAZ and LAZ but not with WLZ may implicate that CS-CFI has the ability to reflect chronic malnutrition among infants. Thus the CS-ICFI summarizes information on feeding practices and can be used to illustrate the strength and magnitude of associations between adequate complementary feeding practices and infant nutritional outcomes in long term.

None of the two-way interactions between the CS-ICFI and the child, maternal, and household characteristics included in the model were statistically significant. Thus, it appears that the magnitude of differences in LAZ and WAZ between feeding tertiles was not conditioned by any of the child, maternal, and household factors. But a Chinese study showed that better feeding practices were more important for children of lower socioeconomic status [12]. Finally the findings of this study support the existing literature despite the fact that the index constructed in this study include hygiene and psychosocial variables as index component. The index is applicable for measuring complementary feeding practices comprehensively which include both feeding behavior and diet quality among HIV exposed infants. However further study is recommended on best approaches of assessing hygiene and psychosocial practices during complementary feeding practices.

\section{Limitation of the study}

Interpersonal measurement error, recall bias, and absence of validated questionnaire to assess hygiene and psychosocial care were the possible limitations of this study. There might be also bias that could be introduced by the data collectors. Equal weights during scoring were given for all feeding practices especially who have binary responses. But the actual effect of those feeding practices 
on nutritional status might not be similar. Since the study used cross-sectional design so that it is difficult to establish cause and effect relationship between nutritional status and summary index.

\section{Conclusion}

Majority of HIV exposed infants had no optimum complementary feeding practices. The CS-ICFI can consistently measure feeding practices of HIV exposed infants older than 9 months. The CS-ICFI was significantly associated especially with chronic indicators of nutritional status. The difference in WAZ and LAZ score between low and high tertiles of the index was biologically meaningful. More rural infants were found in poor index tertile than urban infants. This may suggest that rural infants need more attention than urban infants while designing and implementing complementary feeding interventions.

\section{Competing interests}

The authors declare that they have no competing interests.

\section{Authors' contributions}

$\mathrm{DH}$ conceived and designed the study supervise the data collection, performed analysis, interpretation of data and drafted the manuscript. TB assisted with the design, conception, analysis, and interpretation of data and critically reviewed the manuscript. GB assisted the study design, data interpretation and critically reviewed the manuscript. TS assisted data entry, analysis, interpretation and critically reviewed the manuscript. SB assisted in interpretation of data and drafting and critically reviewed the manuscript. All authors read and approved the final manuscript.

\section{Acknowledgments}

We are highly grateful to HENNA project (Higher Education Network for Applied Human Nutrition between Eastern Africa and Europe) and the ACP/Edulink programme for financing this study. We would like to express our heartfelt gratitude to Hawassa University, Madawalabu University and Woreda health offices for their technical support. We are also very grateful to extend our gratitude to the data collectors, supervisors and study participants.

\section{Author details}

${ }^{1}$ Department of Public Health, College of Medicine and Health Sciences, Madawalabu University, P.o. Box: 139 Bale, Goba, Ethiopia. ${ }^{2}$ Population and family Health Department, College of Public Health and Medical Sciences, Jimma University, Jimma, Ethiopia. ${ }^{3}$ Department of applied human nutrition, School of food sciences and Nutrition, Hawassa University, Hawassa, Ethiopia. ${ }^{4}$ Department of Reproductive Health, College of Medicine and Health Sciences, Bahir Dar University, Bahir Dar, Ethiopia. ${ }^{5}$ Independent Public Health Consultants, Addis Ababa, Ethiopia.

Received: 9 October 2013 Accepted: 11 February 2014

Published: 18 February 2014

\section{References}

1. DeCock K, Fowler M, Mercier E, de VI Saba J, Hoff E, Alnwick D, Rogers M, Shaffer N: Prevention of mother-to-child HIV transmission in resource-poor countries. Translating research into policy and practice. JAMA 2000, 283:1175-1182.

2. Fletcher F, Ndebele P, Kelly M: Infant feeding and HIV in Sub-Saharan Africa: what lies beneath the dilemma? Theor Med Bioeth 2008, 29:307-330.

3. WHO: HIV and Infant Feeding Revised Principles and Recommendations Rapid Advice. Geneva; 2009. http://www.unicef.org/nutritioncluster/files/ IYCFE_WHO_Part1_eng.pdf.

4. WHO U, UNFPA and UNICEF: Guidelines onHIV and infant feeding, Principles and recommendations for infant feeding in the context of HIV and a summary of evidence. 2010. Available at: http://whqlibdocwhoint/ publications/2010/9789241599535_engpdf (date accessd May 17, 2011).

5. Federal ministry of health $(\mathrm{MOH})(\mathrm{HAPCO})$ : Guidelines For Prevention of Mother-to-Child Transmission of HIV In Ethiopia; 2011.

6. Patel D, Bland R, Coovadiad H, Rollinse N, Coutsoudisd A, Newella M: Breastfeeding, HIV status and weights in South African children: a comparison of HIV-exposed and unexposed children. AIDS 2010, 24:437-445.

7. Galler J, Ramsey F, Harrison R, Brooks R, Weiskopf-Bock W: Infant feeding practices in Barbados predicts later growth. J Nutr 1998, 128(1328):1328-1325.

8. Simondom K, Simondom F, Costes R, Delaunay V, Diallo A: Breast-feeding is associated with improved growth in length, but not weight, in rural Senegalese toddlers. American journal of clinical nutrition 2001, 73:959.

9. Piwoz E, Black R, LopezdeRomana G, CreeddeKanashiro H, Brown K: The relationship between infants' preceding appetite, illness, and growth performance and mothers' subsequent feeding practice decisions. Soc Sci Med 1994, 39:851.

10. Mugwaneza P, Umutoni NWS, Ruton H, Rukundo A, Lyambabaje A, Bizimana JdD, Tsague L, Wagner CM, Nyankesha E, Muita J, Mutabazi V, Nyemazi JP, Nsanzimana S, Karema C, Binagwaho A: Under-two child mortality according to maternal HIV status in Rwanda: assessing outcomes within the National PMTCT Program. Pan Afr Med J 2011, 9:37.

11. Arimond M, Ruel M: Summary Indicators For Infant And Child Feeding Practices: An Example From The Ethiopia Demographicand Health Survey 2000. Washington, D.C: Food and nutrition technical assistance project, academy for educational development; 2002.

12. Yan L, Zeng G, Sun Y, Li Z, Dong W, Pan L, Wang Y, Lai J: Methodology of infant and young child feeding index for children aged 6-24 months in China. Wei Sheng Yan Jiu 2012, 41(2):209-214.

13. Srivastava N, Sandhu A: Infant and child feeding index. Indian Journal of Pediatrics 2007, 73:767-770.

14. WHO, UNICEF, IFPRI, UC Davis, USAID, FANTA: Indicators For Assessing Infant And Young Child Feeding Practices. Geneva: Switherland World Health Organization; 2008. http://wwwwhoint/hild_adolescent_health/documents/ 9789241596664/en/indexhtml) date accessd May 25, 2011.

15. Arimond M, Ruel M: Progress In Developing An Infant And Child Feeding Index: An Example Using The Ethiopia Demographic And Health Survey 2000. Fcnd Discussion Paper No.143. Washington, DC: International Food Policy Research Institute (IFPRI); 2002.

16. Moursi M, Trèche $S$, Martin-Prével $Y$, Maire B, Delpeuch F: Association of a summary index of child feeding with diet quality and growth of 6-23 months children in urban Madagascar. Eur J Clin Nutr 2009, 63:718-724.

17. Central statistical agency, Ethiopia: Summary and Statistical Report of the 2007 Population and Housing Census, Population Census Commission, Addis Ababa, Federal Democratic Republic of Ethiopia; 2007.

18. Sidama Economy: Building A Sense Of Community One Step At A Time. Available At Http://Www.Srdforum.Net/10.Html Accessed On September 2012.

19. Tavakol M, Dennick R: Making sense of Cronbach's alpha. Int J Med Ed 2011, 2:53-55.

20. Condo J, Kayumba J, Mock N, Gage A, Greiner T, Rice J, Zyl CV, Mukaminega M, Mukandagano P, Ubarijoro S: Assessment Of Infant Feeding Practices Using Icfi And Its Association With Nutritional Status Among Hiv-Exposed Infants In Rwanda. In Selected Abstracts on HIV and Infant Feeding from the XVIII International AIDS Conference July 18 -23, 2010 Vienna, Austria Abstract number: THPE0811 2010; 2010.

21. Garg A, Chadha R: Index for measuring the quality of complementary feeding practices in rural India. J Health popul nutr 2009, 27(6):763-771.

22. Zhang J, Shi L, Wang J, Wang Y: An infant and child feeding index is associated with child nutritional status in rural China. Early Hum Dev 2009, 85:247-252.

23. Jian-qiang $L$, Shian $Y$, Xiao-guang $Y$, Guan-sheng M: Distribution of feeding index and association between feeding index and growth of infants and young child aged 6-24 months. Wei Sheng Yan Jiu 2005. DOl: cnki: ISSN:1000-8020.0.2005-05-031.

24. Bork K, Cames C, Barigou S, Cournil A, Diallo A: A summary index of feeding practices is positively associated with height-for-age, but only marginally with linear growth, in rural Senegalese infants and toddlers. J Nutr 2012. doi:103945/jn112157602.

25. Sawadogo P, Martin-Pre'vel $Y$, Savy M, Kameli $Y$, Traissac $P$, Traore A: An infant and child feeding index is associated with the nutritional status of 6 to 23 month-old children in Rural Burkina Faso. J Nutr 2006, 136:656-663.

26. Khatoon T, Mollah A, Choudhury A, Islam M, Rahman K: Association between infant and child feeding index and nutritional status results 
from a cross-sectional study among children attending an urban hospital in Bangladesh. Open j access 2011, 29(4).

27. Condo J: Assessment Of Infant Feeding Practices Using A Summary Index And Nutritional Status Among Hiv-Exposed Infants In Rwanda. Phd Dissertation, Public Health And Tropical Medicine, Tulane University; 2009:135p.

28. Ntab B, Simondon K, Milet J, Cisse B, Sokhna C, Boulanger D, Simondonn F: A young child feeding index is not associated with either height-for-age or height velocity in rural Senegalese children. J Nutr 2005, 135:457-466.

29. Ruel M, Menon P: Child feeding practices are associated with child nutritional status in Latin America: innovative uses of the demographic and health survey. J Nutr 2002, 132:1180-1187.

30. Martorell R, Scrimshaw N: The effects of improved nutrition in early childhood: the institute of nutrition of central america and panama (incap) follow-up study. J Nutr 1995, 125:4s.

doi:10.1186/1471-2431-14-49

Cite this article as: Haile et al:: Infant feeding practices among HIV exposed infants using summary index in Sidama Zone, Southern Ethiopia: a cross sectional study. BMC Pediatrics 2014 14:49.

\section{Submit your next manuscript to BioMed Central and take full advantage of:}

- Convenient online submission

- Thorough peer review

- No space constraints or color figure charges

- Immediate publication on acceptance

- Inclusion in PubMed, CAS, Scopus and Google Scholar

- Research which is freely available for redistribution 